\title{
Civicae
}

\section{Educando para a formação de hábitos alimentares saudáveis}

No Brasil a oferta de alimentação escolar principalmente na década de 1950, tinha por objetivo atender principalmente as crianças das escolas públicas, que devido a fatores econômicos apresentam altas taxas de desnutrição, e com isso se caracterizava como assistencialista. No entanto no final da década de 1990 , a alimentação escolar, passa a ser compreendida enquanto direito humano garantido pela Constituição Brasileira, e do Estatuto da Criança e do Adolescente (ECA). Incorporado a este direito o conceito de segurança alimentar, ou seja, a busca pela garantia da alimentação humana de qualidade. Nesse contexto a escola tem papel essencial, na medida em que tem por função a formação integral do indivíduo, ofertando e educando para a formação de hábitos alimentares saudáveis, garantindo qualidade de vida, tendo em vista os documentos orientadores como Lei de Diretrizes e Bases da Educação Nacional (LDBEN), bem como os Parâmetros Curriculares Nacionais (PCN's). Assim este trabalho tem por intuito discutir a importância da formação nutricional dos escolares para uma vida saudável.

Palavras-chave: Escola; Formação; Alimentação; Políticas Públicas.

\section{Educating for the formation of healthy eating habits}

In Brazil, the provision of school meals, mainly in the 1950s, aimed to serve mainly children in public schools, which due to economic factors present high rates of malnutrition, and thus characterized themselves as welfare workers. However, at the end of the 1990s, school meals started to be understood as a human right guaranteed by the Brazilian Constitution, and the Child and Adolescent Statute (ECA). Incorporated into this right is the concept of food security, that is, the search for the guarantee of quality human food. In this context, the school has an essential role, as it has the function of integral training of the individual, offering and educating for the formation of healthy eating habits, guaranteeing quality of life, considering the guiding documents such as the Law of Guidelines and Bases National Education (LDBEN), as well as the National Curriculum Parameters (PCN's). Thus, this work aims to discuss the importance of nutritional education of students for a healthy life.

Keywords: School; Formation; Food; Public policy.

Topic: Políticas Públicas na Educação

Reviewed anonymously in the process of blind peer.
Received: 10/11/2019

Approved: 15/03/2020
Simone Cesario Soares (id

Universidade Estadual do Oeste do Paraná, Brasil

http://lattes.cnpq.br/2595149246400810

http://orcid.org/0000-0002-4219-5729

ccsimone@hotmail.com

Marli Renate von Borstel Roesler (iD)

Universidade Estadual do Oeste do Paraná, Brasil

http://lattes.cnpq.br/8363023458604271

http://orcid.org/0000-0002-5474-7877

marliroesler@hotmail.com
Referencing this:

SOARES, S. C.; ROESLER, M. R. V. B.. Educando para a formação de hábitos alimentares saudáveis. Justitia Liber, v.2, n.1, p.45-51, 2020. DOI: http://doi.org/10.6008/CBPC2674-6646.2020.001.0005 


\section{INTRODUÇÃO}

Ao falar em saúde estamos considerando diversos fatores como por exemplo: a qualidade da água que consumimos e do ar que se respiramos, as condições de fabricação e uso de equipamentos nucleares ou bélicos, o consumismo desenfreado e a miséria, a degradação social e a desnutrição, os estilos de vida pessoais e as formas de inserção das diferentes parcelas da população no mundo do trabalho. Implica, ainda, na consideração dos aspectos éticos relacionados ao direito à vida e à saúde, aos direitos e deveres, às ações e omissões de indivíduos e grupos sociais, dos serviços privados e do poder público.

Nesse contexto assegurar a alimentação saudável constitui um direito de todos, previsto na Constituição Brasileira (BRASIL, 1988). E o Estatuto da Criança e do Adolescente (ECA) diz que é dever da família, da comunidade, da sociedade em geral e do poder público assegurar, com absoluta prioridade, os direitos referentes à vida, à saúde e à alimentação (BRASIL, 1990).

E neste contexto a escola como agente transformadora pode atuar como ponto estratégico na formação de crianças e jovens, na medida em que influência, na qualidade de vida de seus alunos através das várias práticas educacionais, oferecendo e formando para hábitos alimentares saudáveis, como previstos nas leis e diretrizes curriculares.

\section{METODOLOGIA}

O trabalho discute e analisa a relação da segurança alimentar, bem como a formação para hábitos alimentares saudáveis das crianças e jovens através da escola, a partir das políticas públicas, a fim de promover a qualidade de vida. E para isso foram realizadas revisões a partir de artigos científicos publicados, bem como da literatura existente e discussões recentes acerca da temática direito à alimentação saudável.

\section{REVISÃO TEÓRICA}

Na década de 1940, o Brasil teve a primeira proposta de oferta de alimentação escolar criada pelo Instituto Nacional de Nutrição, a iniciativa não prosseguiu devido à falta de recursos financeiros. A partir da década de 1950, foi elaborado o Plano Nacional de Alimentação e Nutrição, denominado Conjuntura Alimentar e o Problema da Nutrição no Brasil, programa de merenda escolar, de âmbito nacional e de gestão pública, Campanha Nacional de Merenda Escolar (CNME), de caráter assistencialista, visava combater a desnutrição, atendendo crianças de baixa renda, ao mesmo tempo em que atendia aos interesses da indústria, na medida em que absorvia os excedentes produzidos (SILVA et al., 2018; PAIVA et al., 2016).

Os governos devem garantir a efetivação do direito à alimentação para os alunos matriculados nas escolas públicas e filantrópicas de educação infantil e de ensino fundamental que constem do censo escolar, realizado pelo Instituto Nacional de Estudos e Pesquisas Educacionais Anísio Teixeira, do Ministério da Educação (INEP/MEC, 2008).

Em 1979 passou a ser denominado de Programa Nacional de Alimentação Escolar (PNAE). A partir da Constituição de 1988, a federação, estado e municípios passaram a serem responsáveis pelo custeio, 
inclusive com previsão orçamentária. Em 1994 foi instituída por meio da Lei no 8.913 (BRASIL, 1994), a descentralização das políticas de alimentação escolar, a partir de convênios com municípios, a partir das secretarias de Educação, estas passam a desempenhar funções antes exercidas pelo gerenciamento do próprio PNAE.

Com a promulgação da Constituição Federal de 1988, foi possibilitada maior participação da sociedade civil (BRASIL, 1988), a partir do texto da nova constituição oficializa a democracia representativa e participativa, incorporando a participação da comunidade/sociedade em geral na gestão das políticas públicas. Com esta nova concepções de gestão participativa na década de 1990 foram constituídos os conselhos de controle social.

\section{RESULTADOS E DISCUSSÃO}

Para uma qualidade de vida é indispensável, a oferta e o acesso de alimentos saudáveis. A alimentação saudável enquanto um direito fundamental e acessível a todos, em quantidade e qualidade, garantida pela Constituição Brasileira (BRASIL, 1988). Baseada em práticas alimentares promotoras da saúde, sem nunca comprometer o acesso a outras necessidades essenciais. Esse é um direito do brasileiro, um direito de se alimentar devidamente, respeitando particularidades e características culturais de cada região.

Entre as décadas de 1980 e 1990, o conceito de segurança alimentar passou a incorporar também as noções de acesso a alimentos seguros e de qualidade (nutricional, biológica, sanitária e tecnológica), produzidos de forma sustentável, equilibrada e culturalmente aceitável. Essa visão foi consolidada nas declarações da Conferência Internacional de Nutrição, realizada em Roma, em 1992, pela FAO e pela Organização Mundial da Saúde (OMS). Agrega-se definitivamente o aspecto nutricional e sanitário ao conceito, que passa a ser denominado Segurança Alimentar e Nutricional (VALENTE, 2002).

Para haver segurança alimentar considera-se necessário ter poder aquisitivo para adquirir alimentos. No entanto esta não é uma realidade para muitas pessoas no Brasil. Particularmente na economia brasileira, uma parcela substancial da população brasileira tem rendimentos tão baixos que as coloca, em uma situação de insegurança alimentar. A alimentação não diz respeito apenas ao ato de ingerir um alimento, mas faz parte de um contexto cultural, étnico e social.

A segurança alimentar e nutricional tem por intuito ampliar o acesso a alimentos principalmente por meio da agricultura familiar tradicional, promovendo a biodiversidade e a utilização de recursos sustentáveis. Na busca pela efetivação deste direito, se faz necessária uma Política de Segurança Alimentar e Nutricional a partir de um conjunto de ações planejadas para garantir a oferta e o acesso aos alimentos para toda a população. Deve-se dar de maneira sustentável, ou seja, produzido em condições que permitam sua manutenção, em longo prazo. Em se tratando de políticas públicas a mesma deve buscar o engajamento da sociedade civil organizada, em seus diferentes setores, saúde, educação, trabalho, agricultura, desenvolvimento social, meio ambiente, produção, comercialização, controle de qualidade e o acesso ao consumo (BRASIL, 2004). 
A partir do Sistema Nacional de Segurança Alimentar e Nutricional (SISAN), os órgãos governamentais dos três níveis de governo e as organizações da sociedade civil devem atuar conjuntamente na formulação e implementação de políticas e ações de combate à fome e de promoção da Segurança Alimentar e Nutricional, e ainda no acompanhamento, monitoramento e avaliação da situação nutricional da população, definindo direitos e deveres do poder público, da família, das empresas e da sociedade (BRASIL, 2006).

A Agenda 2030 da ONU, os Objetivos de Desenvolvimento Sustentável (ODS) são contempladas 17 metas globais estabelecidas pela Assembleia Geral das Nações Unidas. Os ODS são parte da Resolução 70/1 da Assembleia Geral das Nações Unidas (ONU): "Transformando o nosso mundo: a Agenda 2030, para o Desenvolvimento Sustentável". Os ODS abrangem questões de desenvolvimento social e econômico, incluindo pobreza, fome, saúde, educação, aquecimento global, igualdade de gênero, água, saneamento, energia, urbanização, meio ambiente e justiça social.

Desta forma a boa nutrição é fundamental para o bem-estar das crianças e jovens para o alcance dos Objetivos de Desenvolvimento Sustentável (ODS). Ela precisa ser colocada no centro da política governamental e apoiada pelas principais partes interessadas, incluindo a sociedade civil e o setor privado. A preocupação com a vulnerabilidade social, expressa pela condição de alimentação insuficiente é o primeiro dos ODM: Erradicar a Pobreza Extrema e a Fome. Ele foi reiterado nos ODS, apenas desdobrado em dois objetivos diferentes: erradicar a pobreza em todas as suas formas no Mundo; e erradicar a fome, alcançar a segurança alimentar e a melhoria da nutrição, e promover a agricultura sustentável.

No Brasil o PNAE visa satisfazer as necessidades nutricionais do aluno no período em que ele permanece na escola, além de contribuir com hábitos alimentares saudáveis, tem por objetivo contribuir para o crescimento e o desenvolvimento biopsicossocial, a aprendizagem, o rendimento escolar e a formação de hábitos alimentares saudáveis dos alunos, por meio de ações de educação alimentar e nutricional, e da oferta de refeições que cubram as suas necessidades nutricionais durante o período letivo (BRASIL, 2009).

A alimentação escolar é um direito humano e social de todas as crianças e adolescentes que estão nas escolas e um dever do Estado (governo federal, estadual, distrital e municipal). Esse dever do Estado é efetivado mediante a execução do PNAE, coordenado pelo Fundo Nacional de Desenvolvimento da Educação (FNDE).

Se no início da implantação de políticas públicas voltadas para a alimentação escolar, a grande preocupação era com a desnutrição, na atualidade há uma inversão do quadro, ou seja, a inversão nutricional, com a redução da desnutrição e um aumento significativo da obesidade, considerada doença universal, e vista como principal problema de saúde pública. O excesso de peso geralmente está associado ao excesso de comida e as más escolhas alimentares, com preferências aos alimentos ricos em açúcares e gorduras (FREITAS et al., 2009).

Se por um lado a escola, através das políticas públicas governamentais, tem uma função essencial, que é a de garantir durante o período escolar, ao menos uma refeição as crianças e adolescentes, principalmente as mais vulneráveis, por outro tem uma função também primordial no processo educacional, o de educar para a saúde, incentivando, o consumo de alimentos adequados nutricionalmente a cada faixa 
etária, orientando e claro oferecendo alimentação de boa qualidade e principalmente saudável. A escola tem grande poder de influência sobre as escolhas dos estudantes, principalmente na formação de hábitos alimentares, mais saudáveis.

Cabe à escola a orientação nutricional, conscientização e formação de novos hábitos alimentares, priorizando a importância da alimentação saudável, e consequentemente mais saúde a nossos alunos. Esta proposta vem reafirmar o previsto na Lei $n^{\circ} 11.947 / 2009$, em seu Art. 2 으o diretrizes da alimentação escolar:

II - A inclusão da educação alimentar e nutricional no processo de ensino e aprendizagem, que perpassa pelo currículo escolar, abordando o tema alimentação e nutrição e o desenvolvimento de práticas saudáveis de vida, na perspectiva da segurança alimentar e nutricional. (BRASIL, 2009)

Assim a escola através dos Parâmetros Curriculares Nacionais (PCNs), a partir da Lei de Diretrizes e Bases da Educação Nacional (LDBEN) apresenta dentro de sua proposta temática, a Saúde, através dos temas transversais, abordando alimentação e nutrição. Desta forma, a necessidade de se tratar da alimentação saudável em âmbito escolar foi publicada a Portaria Interministerial de № 1.010, 2006, que trata da Instituição das diretrizes para a Promoção da Alimentação Saudável nas Escolas de educação infantil, fundamental e nível médio das redes públicas e privadas, em âmbito nacional, conforme consta abaixo:

Art. 5o Para alcançar uma alimentação saudável no ambiente escolar, devem-se implementar as seguintes ações: VII - estimular e auxiliar os serviços de alimentação da escola na divulgação de opções saudáveis e no desenvolvimento de estratégias que possibilitem essas escolhas; $X$ - incorporar o tema alimentação saudável no projeto político pedagógico da escola, perpassando todas as áreas de estudo e propiciando experiências no cotidiano das atividades escolares. (BRASIL, 2006)

Assim uma mudança do hábito alimentar seria possível a partir da integração da nutrição ao ensino, representaria uma forma mais eficaz de intervenção nutricional (PIETRUSZYNSKI et al., 2010), a partir do momento em que o aluno adquire clareza do que está comendo, bem como do resultado desse consumo para seu corpo, sua saúde, ou seja, através do conhecimento alimentar do indivíduo seria de fato um caminho para se alcançar uma mudança profunda e consciente.

Tendo em vista esta necessidade de educar para a alimentação saudável, promovendo e busca a garantia de práticas alimentares saudáveis no espaço escolar, o Ministério da Saúde, por meio da Coordenação-geral da Política de Alimentação e Nutrição (CGPAN), instituiu a Portaria Interministerial no 1.010 de 8 de maio de 2006, estabelece diretrizes para a promoção da alimentação saudável em todas as etapas (educação infantil, ensino fundamental e ensino médio) das escolas da rede pública e privada (BRASIL, 2006).

Formar para uma nutrição saudável, representaria um processo cognitivo do indivíduo, possibilitando atitudes e comportamentos desejados. A escola a partir do ensino através de práticas alimentares habilitaria seus alunos para uma alimentação saudável, ou seja, o conhecimento pode mudar hábitos (VARGAS et al., 2007). A escola ao ofertar novas informações sobre alimentação e nutrição, auxilia na promoção da ampliação do conhecimento individual que poderá resultar em melhorias no 
comportamento alimentar, do aluno favorecendo não só a manutenção como na recuperação do estado nutricional (SILVA et al., 2013; TORAL et al., 2009).

Desta forma a escola adotando um estilo de vida mais saudável entre as crianças e adolescentes à seria fundamental para o delineamento adequado de materiais educativos e intervenções nutricionais. Assim a função da escola vai além de ofertar alimentos saudáveis, exerce também à função formadora de novos hábitos, novos modos de conceber saúde, promotora de boas práticas, a fim de gerar pessoas mais saudáveis e conscientes do quão importante é o papel da escolha certa, da alimentação em nossa vida. A escola representa um espaço de formação importante para o desenvolvimento dos indivíduos através de ações de melhoria das condições de saúde e do estado nutricional das crianças e dos jovens, pois tem abrangência da saúde a partir da educação (SCHMITZ et al., 2008).

Ao mesmo tempo segundo Soares et al. (2009), coloca que a escola traz em sua matriz curricular conteúdos escassos sobre alimentação escolar, falta informação nos materiais didáticos, a falta de capacitação. E em algumas escolas, a preparação do alimento pode ser ainda mais comprometida na medida em que se tem falta de estrutura física e recursos humanos.

Assim cabe à escola oferecer alimentação saudável e equilibrada, bem como orientar seus alunos na prática de bons hábitos de vida, na busca por um rendimento escolar adequado (PERNETA, 1980; MONTEIRO; CAMELO, 2007). As consequências principais da alimentação inadequada no período escolar podem ser caracterizadas como alteração do aprendizado e da atenção, aumento do número de repetências, carências nutricionais ou decorrentes do excesso de alimentos (PECKENPAUGH et al., 1997; KACHANI et al., 2005).

A alimentação escolar deixa de ter uma função apenas de suprimento nutricional e assistencialista como evidenciado principalmente nas décadas de 1940 e 1950 pelas políticas públicas, e passa na atual conjuntura a ter papel formativo, ou seja, educação para uma boa alimentação e por consequência boa saúde. Neste contexto a educação nutricional é um processo de formação de longo prazo, ou seja, deve ocorrer de forma contínua (RODRIGUES et al., 2008). Assim a escola numa perspectiva de formação integral, através das várias possibilidades metodológicas de ensino aprendizagem, pode capacitar o indivíduo a escolhas nutricionais saudáveis (COSTA et al., 2001).

A educação como principal propulsor da mudança, necessita de novos métodos de ensino, colocando o estudante em contato com o ambiente externo à sala de aula, em contato direto com a natureza. Aproveitando o conhecimento popular, para potencializar a sustentabilidade local e regional (BOFF, 2012). A alimentação adequada deve ser considerada como essencial a saúde da população. Assim fez-se necessário ter uma compreensão clara do que é uma boa nutrição (ZANCUL, 2008). E através do conhecimento criamse mecanismo para escolhas adequadas, possibilitando qualidade de vida, e bons hábitos alimentares que seguiram para a vida adulta.

\section{CONCLUSÕES}

Assim na busca pela garantia do direito à alimentação, a partir do conceito de segurança alimentar, as políticas públicas através de ações intersetoriais, podem garantir tanto a oferta de alimentação escolar de 
qualidade, quanto à formação de hábitos alimentares saudáveis a partir de ações pedagógicas efetuadas através da escola, e não apenas pelo professor, mas pela comunidade escolar como um todo. Através da efetivação de ações de conscientização, bem como experiências, contribuindo para a melhoria da qualidade de vida de nossos alunos, algo a ser usufruída durante toda sua vida.

\section{REFERÊNCIAS}

BOFF, L.. Sustentabilidade: o que é?. Petrópolis: Vozes, 2017.

Brasil. Lei n. 11.346, de 15 de setembro de 2006. Cria o Sistema Nacional de Segurança Alimentar e Nutricional SISAN, com vistas em assegurar o direito humano à alimentação adequada e dá outras providencias. Brasília: DOU, 2006.

BRASIL. Lei n. 8.069, de 13 de julho de 1990. Estatuto da Criança e do Adolescente - ECA. Brasília: DOU, 1990. Brasil. Lei n. 8.913 de 12 de julho de 1994. Dispõe sobre a municipalização da merenda escolar. Brasília: DOU, 1994.

BRASIL. Ministério da Educação. Resolução/CD/ FNDE n o 38, de 16 de julho de 2009. Dispõe sobre o atendimento da alimentação escolar aos alunos da educação básica no Programa Nacional de Alimentação Escolar (PNAE). Diário Oficial da União 2009; 17 jun.

BRASIL. Presidência da República. Constituição da República Federativa do Brasil de 1988. Brasília: Casal Civil, 1988.

BRASIL. Princípios e diretrizes de uma política de segurança alimentar e nutricional. Brasília: CONSEA, 2004.

COSTA, E. Q.; RIBEIRO, V. M. B.; RIBEIRO, E. C. O.. Programa de alimentação escolar: espaço de aprendizagem e produção de conhecimento. Rev. Nutr., Campinas, v.14, n.3, p.225-9, 2001.

FREITAS, A. S. S.; COELHO, S. C.; RIBEIRO, R. L.. Obesidade infantil: influência de hábitos alimentares inadequados. Saúde \& Ambiente em Revista, Rio de Janeiro, v.4, n.2, p.914, 2009.

ONU. Organização das Nações Unidas. Declaração Universal dos Direitos Humanos da ONU. Transformando Nosso Mundo: a Agenda 2030 para o Desenvolvimento Sustentável. Nova York: ONU, 2015.

PAIVA, J. B.; FREITAS, M. C. S.; SANTOS, L. A.. Significados da alimentação escolar segundo alunos atendidos pelo Programa Nacional de Alimentação Escolar. Ciências e Saúde Coletiva, v.21, n.8, p.2507-2516, 2016. DOI: http://doi.org/10.1590/1413-81232015218.07562015

PECKENPAUGH, N. J.; POLEMAN, C. M.. Nutrição: essência e dietoterapia. 7 ed. São Paulo: Roca, 1997.

PERNETA, C.. Alimentação da criança. 7 ed. São Paulo: Fundo Editorial Byk-Procienx, 1980.

PIETRUSZYNSKI, E. B.; ALBIERO, K. A.; PÖPPER, G.; TEIXEIRA, $P$. F.. Práticas pedagógicas envolvendo a alimentação no ambiente escolar: apresentação de uma proposta. Revista Teoria e Prática da Educação, v.13, n.2, p.223-229, 2010. DOI: https://doi.org/10.4025/tpe.v13i2.15348

RODRIGUES, L. P. F.; RONCADA, M. J.. Educação nutricional no Brasil: evolução e descrição de propostas metodológicas para escolas. Com. Ciências Saúde, v.19, n.4, p.315-322, 2008.

SCHMITZ, B. A. S.; RECINE, E.; CARDOSO, G. T.; SILVA, J. R. M.; AMORIM, N. F. A.; BERNARDON, R.; RODRIGUES, M. L. C. F.. A escola promovendo hábitos alimentares saudáveis: uma proposta metodológica de capacitação para educadores e donos de cantina escolar. Cadernos de Saúde Pública, Rio de Janeiro, v.24, n.2, p.S312-S322, 2008. DOI: https://doi.org/10.1590/S0102-311X2008001400016

SILVA, E. O.; SANTOS, L. A.; SOARES, M. D.. Alimentação escolar e constituição de identidades dos escolares: da merenda para pobres ao direito à alimentação. Caderno de Saúde Pública, v.34, n.4, p.1-13, 2018.

SILVA, M. X.; COSTA, J. D.; UEHARA, A.; FREITAS, E. C. B. PIERUCCI, A. P. T. R.; PORTO, C. P. M.. Projeto piloto: considerações de alunos do ensino fundamental sobre método de educação alimentar. Revista em Extensão, Uberlândia, v.12, n.2, p.51-64, 2013.

SOARES, A. C. F.; LAZZARI, A. C. M.; FERDINANDI, M. N.. Análise da importância dos conteúdos da disciplina de Educação Nutricional no ensino fundamental segundo professores de escolas públicas e privadas da cidade de Maringá/Paraná. Revista Saúde e Pesquisa, Maringá, v.2, n.2, p.179-184, 2009.

TORAL, N.; CONTI, M. A.; SLATER, B.. A alimentação saudável na ótica dos adolescentes: percepções e barreiras à sua implementação e características esperadas em materiais educativos. Caderno de Saúde Pública, Rio de Janeiro, v.25, n.11, p.2386-2394, 2009.

VALENTE, F. L. S.. Do combate à fome à Segurança Alimentar e Nutricional: o direito humano à alimentação adequada. In: VALENTE, F. L. S.. Direito humano à alimentação adequada: desafios e conquistas. São Paulo: Cortez, 2002. p.40-43.

VARGAS, V. D. S.; LOBATO, R. C.. O desenvolvimento de práticas alimentares saudáveis: uma estratégia de educação nutricional no ensino fundamental. Vita et Sanitas, Trindade, v.1, n.1, 2007.

ZANCUL, M. S.. Consumo alimentar de alunos nas escolas de ensino fundamental em Ribeirão Preto (SP). Dissertação (Mestrado) - Universidade de São Paulo, São Paulo, 2004.

A CBPC - Companhia Brasileira de Produção Científica (CNPJ: 11.221.422/0001-03) detém os direitos materiais desta publicação. Os direitos referem-se à publicação do trabalho em qualquer parte do mundo, incluindo os direitos às renovações, expansões e disseminações da contribuição, bem como outros direitos subsidiários. Todos os trabalhos publicados eletronicamente poderão posteriormente ser publicados em coletâneas impressas sob coordenação da Cognitionis Publishing, da Companhia Brasileira de Produção Científica e seus parceiros autorizados. Os (as) autores (as) preservam os direitos autorais, mas não têm permissão para a publicação da contribuição em outro meio, impresso ou digital, em português ou em tradução. 